\title{
Bachelor's degree in German Studies and then? The professional development of the 2008 BA German Graduates from Universiti Putra Malaysia
}

\begin{abstract}
Objective: An ongoing tracer study project -January 2014 to October 2015 -aims to provide more comprehensive data on the professional development of BA German graduates from UPM.

Methodology/Technique: The group of 2008 graduates has been chosen to provide initial data via in-depth interviews, questionnaires and social media groups, which allowed the conclusion that studying BA German at UPM combined with a business-related minor subject is a proven formula for a successful and quick entry into the Malaysianjob market.

Findings: Many have changed their career paths in order to gain higher incomes, face greater challenges and enjoy better career opportunities. Some graduates became language teachers (Mandarin, English, Bahasa Malaysia and German) at primary and residential schools, colleges and universities. Furthermore, several opted for Master's degrees.

Novelty: The comprehensive study on the „Future Direction of the Language Education in Malaysia"(2010) concluded that graduates of language majors from Malaysian universities do not have any problem in securing employment either in the public or the private sector.

A survey related to the professional development of former Bachelor of Arts in Foreign Languages (German)-students confirmed that the majority of graduates from University Putra Malaysia found employment in the corporate or education sector shortly after finishing their studies.
\end{abstract}

Keyword: 2008 graduates; BA German curriculum; BA German programme; Malaysia job market; Professional development of UPM graduates; Tracer study; UPM 